\title{
UTILIZAÇÃO DA METODOLOGIA DMAIC PARA REDUÇÃO DO CUSTO DE TRANSFORMAÇÃO NA ACIARIA DA VOTORANTIM SIDERURGIA EM RESENDE*
}

\author{
Pedro Henrique Coutinho ${ }^{1}$ \\ Alencar Souza Santos ${ }^{2}$ \\ José Fernando Cerqueira ${ }^{3}$ \\ Paulo Roberto Campos Franco ${ }^{4}$ \\ Edson Gomes ${ }^{5}$ \\ Jonathan Nicholas da Silva Navarro ${ }^{6}$ \\ Mário Cezar Radich ${ }^{7}$
}

\section{Resumo}

Este trabalho teve como objetivo a redução do custo de transformação da Aciaria de Resende (Votorantim Siderurgia), visando à redução do Cash Cost do tarugo, ponto fundamental no atual cenário econômico da siderurgia brasileira. Para priorizar as ações, otimizar recursos e tratar o tema de forma estruturada foi utilizada a metodologia DMAIC na execução deste projeto. Como resultado houve redução no custo de transformação, alcançado por melhorias nas linhas de Energia Elétrica, Ligas, Escorificantes, Eletrodos e Outras Variáveis.

Palavras-chave: DMAIC; Custo de transformação; Melhoria contínua; Aciaria elétrica.

\section{USING THE DMAIC METHODOLOGY FOR TRANSFORMATION COST REDUCTION AT VOTORANTIM'S MELTSHOP IN RESENDE}

\begin{abstract}
The objective of this work was the reduction of transformation cost at Votorantim's Meltshop in Resende-RJ, aiming decrease the billet Cash Cost, important point in current economic scenario of Brazilian steel industry. The DMAIC methology was used to priorize the actions, optimize resources and manage the issue in a structured way. As a result there was a reduction of the transformation cost achieved by improvements in Electrical Energy, Alloys, Electrodes and Other Costs.
\end{abstract}

Keywords: DMAIC; Transformation cost, Continuous improvement, Meltshop.

1 Engenheiro Metalurgista, Engenheiro de Processos, Aciaria Elétrica, Votorantim Siderurgia, Resende, Rio de Janeiro, Brasil.

2 Técnico em Mecânica, Coordenador de Produção, Aciaria Elétrica, Votorantim Siderurgia, Resende, Rio de Janeiro, Brasil.

3 Técnico em Mecânica, Técnico Especialista, Aciaria Elétrica, Votorantim Siderurgia, Resende, Rio de Janeiro, Brasil.

4 Técnico em Metalurgia, Técnico Especialista, Aciaria Elétrica, Votorantim Siderurgia, Resende, Rio de Janeiro, Brasil.

5 Economista, Analista de Custo, Aciaria Elétrica, Votorantim Siderurgia, Resende, Rio de Janeiro, Brasil.

6 Engenheiro Metalurgista, Gerente, Aciaria Elétrica, Votorantim Siderurgia, Resende, Rio de Janeiro, Brasil.

7 Técnico em Elétrica, Consultor, Aciaria Elétrica, Votorantim Siderurgia, Resende, Rio de Janeiro, Brasil. 


\section{INTRODUÇÃO}

No atual cenário da siderurgia brasileira, que sofre com a concorrência do aço importado chegando ao mercado brasileiro a baixo custo, a redução dos custos de produção é vital para a continuidade da operação das usinas siderúrgicas nacionais. Para isso, é necessário ter um controle criterioso dos pacotes de custo, além de um conjunto de ações e investimentos que contribuam para aumento de eficiência e redução de consumos específicos das matérias primas.

\section{MATERIAIS E MÉTODOS}

O método utilizado para construção do trabalho foi o DMAIC, que consiste nas etapas de Definição, Medida, Analisar, Melhorar e Controlar. Esta metodologia foi escolhida para auxiliar na priorização e na otimização de recursos, garantindo ganhos importantes, porém sem necessidade de grandes investimentos.

\begin{tabular}{|c|c|c|}
\hline$\underset{\text { Votorantim }}{\text { V/ }}$ & \multicolumn{2}{|c|}{ Redução do Custo de Transformação do Aço na GAE } \\
\hline \multicolumn{3}{|c|}{ BRAINSTORMING } \\
\hline Número & Variável & Área \\
\hline$x_{1}$ & Energia Elétrica - Direta & Aciaria \\
\hline $\mathrm{x}_{2}$ & Ferro Silicio Manganês & Aciaria \\
\hline$x_{3}$ & Eletrodos $(\mathrm{kg})$ & Aciaria \\
\hline$x_{4}$ & Transporte Interno & Aciaria \\
\hline$x_{5}$ & Cal Calcitica & Aciaria \\
\hline$x_{6}$ & Mats. Auxiliares & Aciaria \\
\hline $\mathrm{x}_{7}$ & Gás Natural & Aciaria \\
\hline$X_{8}$ & Coque Petroleo & Aciaria \\
\hline$x_{9}$ & Oxigênio Comprado & Aciaria \\
\hline $\mathrm{X}_{10}$ & Ferro Silicio & Aciaria \\
\hline$x_{11}$ & Serviços na Operação & Aciaria \\
\hline
\end{tabular}

Figura 1. Visão parcial do Brainstorming do Projeto

Inicialmente, foi realizado um Brainstorming a fim de levantar todos os X's que impactam no custo de transformação, conforme Figura 1. Em seguida, estes itens foram distribuídos em um fluxograma, onde foi obtido o Mapeamento do Processo, conforme Figura 2.

Após conhecer os X's do projeto, foi elaborada a Matriz Causa \& Efeito, que tem como objetivo de estimar o efeito/consequência de cada $X$ levantado no $Y$ do projeto, que neste caso é o custo de transformação. Os itens considerados como alto impacto são os pertencentes ao primeiro quartil. A matriz resumida pode ser vista na figura 3 .

Na mesma matriz foi adicionada uma coluna que contempla o esforço requerido para atacar cada item (X's). Com esta informação, é possível criar a Matriz Esforço $x$ Impacto, que é importante para priorizar as ações do trabalho. Ela pode ser vista na figura 4. 


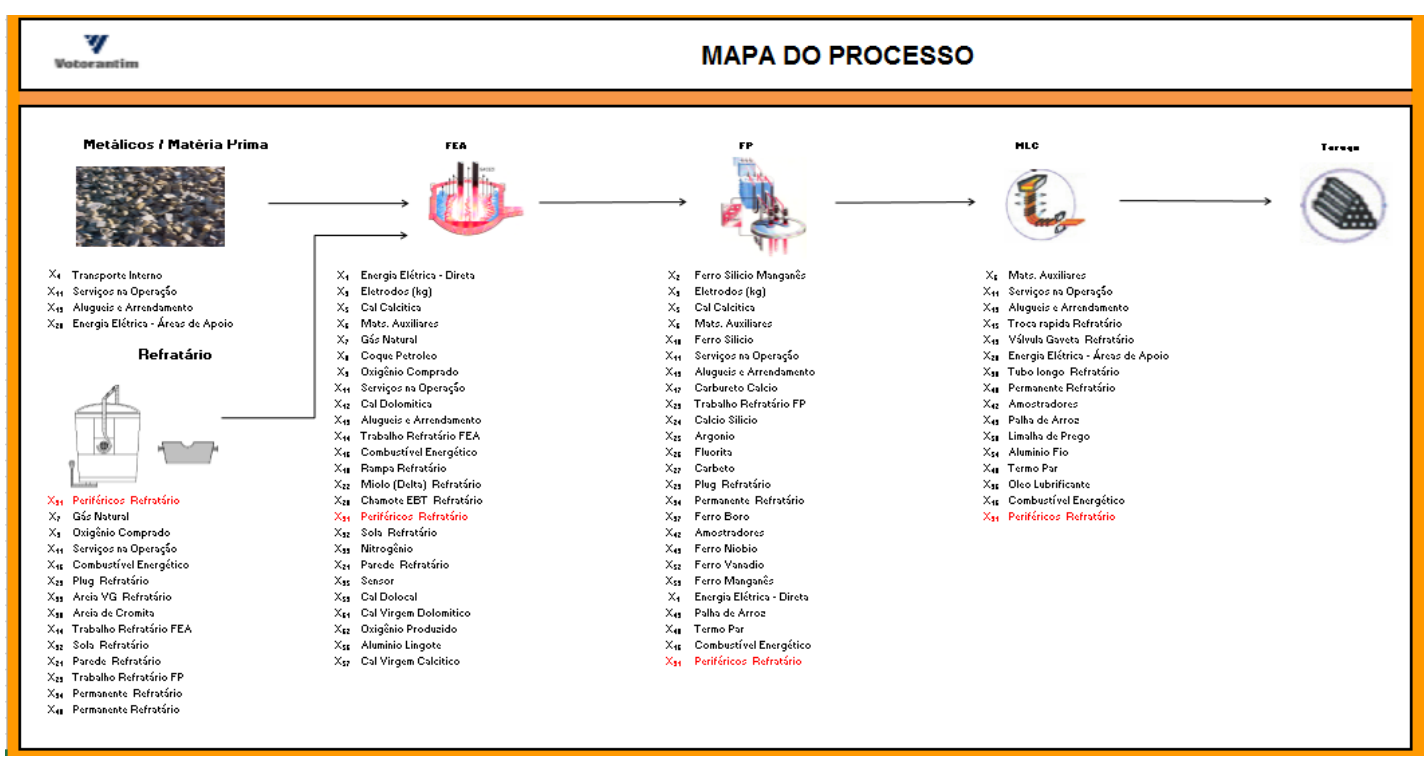

Figura 2. Mapa do Processo

\begin{tabular}{|c|c|c|c|c|}
\hline \multicolumn{4}{|c|}{ MATRIZ CAUSA \& EFEITO } & 60 \\
\hline \multicolumn{2}{|r|}{ X's do Processo } & $\begin{array}{l}\text { Impacto Custo } \\
\text { (RS/t) }\end{array}$ & $\begin{array}{l}8 \\
\mathrm{~g} \\
\mathrm{~g}\end{array}$ & Esforço Total \\
\hline $\mathrm{x} 1$ & Energia Elétrica - Direta & $\mathrm{x}$ & Alto & Baixo \\
\hline$x 4$ & Transporte Interno & $\mathrm{x}$ & Alto & Alto \\
\hline$x 2$ & Ferro Silicio Manganês & $\mathrm{x}$ & Alto & Baixo \\
\hline 83 & Eletrodos (kg) & $\mathrm{x}$ & Alto & Baixo \\
\hline$x_{6}$ & Mats. Auxiliares & $\mathrm{x}$ & Alto & Baixo \\
\hline$\times 22$ & Energia Elétrica - Áreas de Apoio & $\mathrm{x}$ & Alto & Alto \\
\hline$\times 5$ & Cal Calcitica & $\mathrm{x}$ & Alto & Baixo \\
\hline $\mathrm{x} 11$ & Serviços na Operação & $\mathrm{x}$ & Alto & Alto \\
\hline$x 9$ & Oxigênio Comprado & $\mathrm{x}$ & Alto & Alto \\
\hline 87 & Gás Natural & $\mathrm{x}$ & Alto & Alto \\
\hline 88 & Coque Petroleo & $\mathrm{x}$ & Alto & Alto \\
\hline $\mathrm{x} 10$ & Ferro Silicio & $\mathrm{x}$ & Alto & Baixo \\
\hline $\mathrm{x} 14$ & Alugueis e Arrendamento & $\mathrm{x}$ & Alto & Alto \\
\hline$x 12$ & Cal Dolomitica & $\mathrm{x}$ & Baixo & Alto \\
\hline
\end{tabular}

Figura 3. Matriz Causa x Efeito (Simplificada)

A partir da Matriz Esforço x Impacto (Figura 4), foram estruturadas as frentes de trabalho. As frentes com Prioridade 1 possuem alto retorno e que necessitam de menor esforço. As frentes prioridade 2 necessitam baixo esforço, porém o retorno não é tão elevado. Já os X's que são relevantes pro custo, porém possuem maior esforço, devem ser tratados dentro da rotina (definição de indicador e meta, acompanhamento do indicador e elaboração de plano de ação em caso de desvio de meta).

\section{RESULTADOS E DISCUSSÃO}

Os principais pontos que foram atacados no trabalho foram: i) eletrodos, ii) Ligas (FeSi,FeSiMn e CaSi), iii) Carbureto de Cálcio, iv) Energia Elétrica. Abaixo segue evolução do custo de transformação (custos relativos a carburantes, ligas, 
escorificantes, energia elétrica, gases, carbureto de Cálcio, eletrodos) ao longo de 2014, na Figura 5.

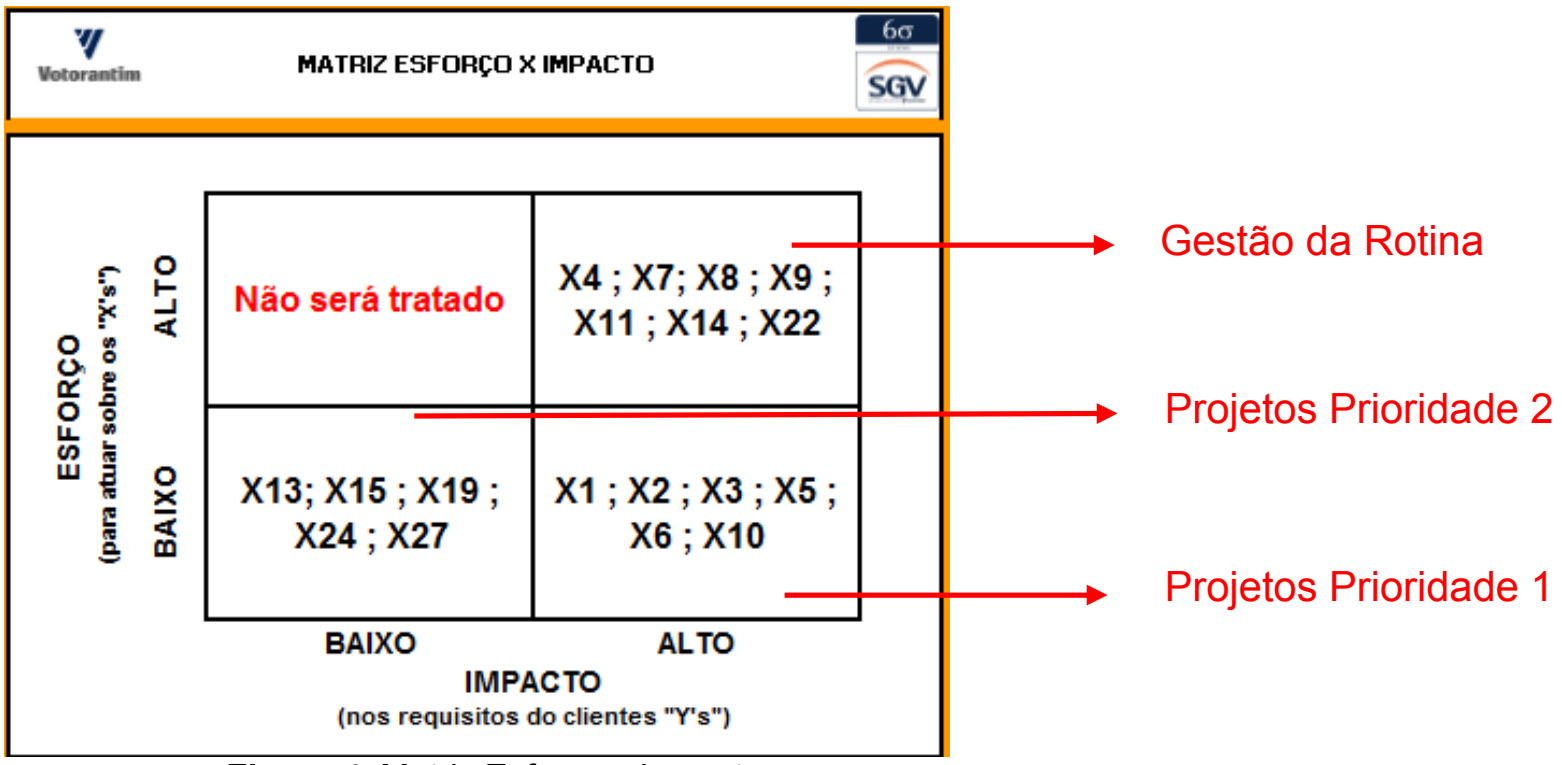

Figura 4. Matriz Esforço $x$ Impacto

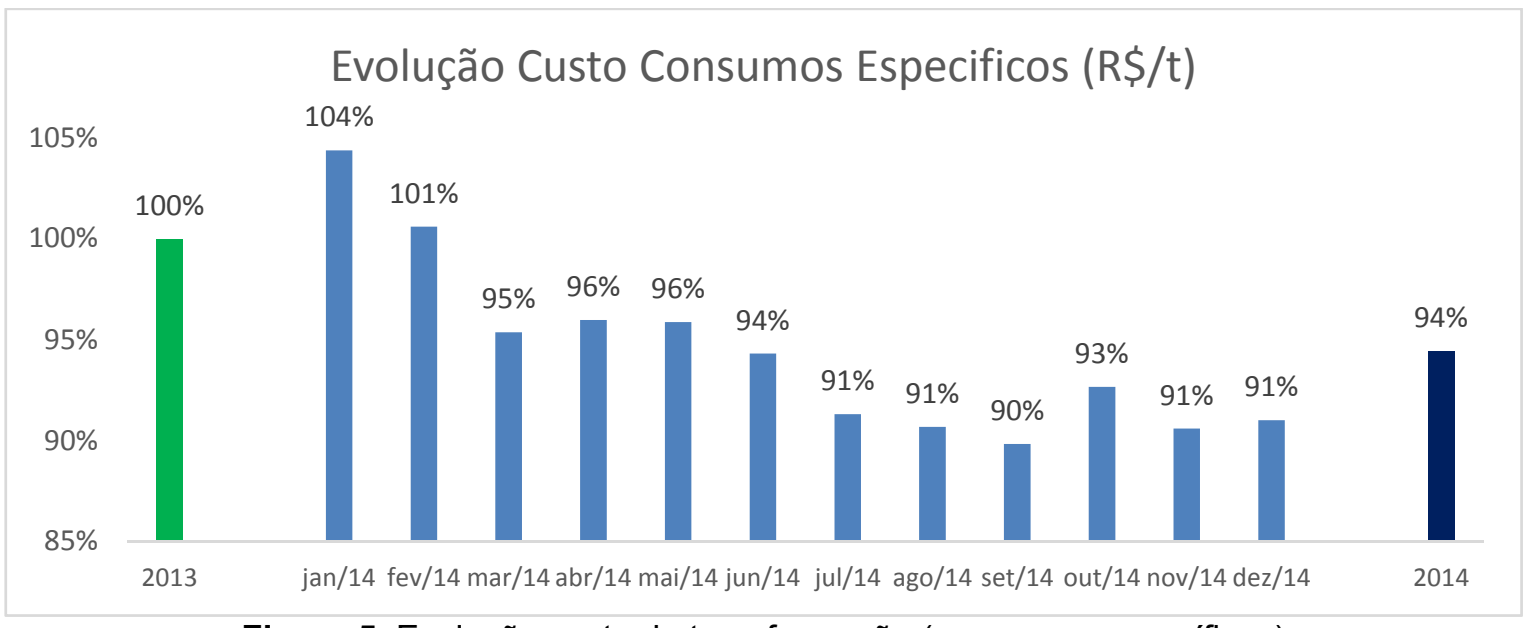

Figura 5. Evolução custo de transformação (consumos específicos)

\subsection{Eletrodos}

O consumo de eletrodos, segundo Jaccard [1], ocorre no sentido i) vertical devido ao efeito do arco elétrico na ponta do eletrodo, e é proporcional ao quadrado da corrente; ii) horizontal devido ao efeito de oxidação do eletrodo. Além disso, o consumo é fortemente impactado por quebras de eletrodo, seja por ajuste inadequado dos parâmetros do regulador de eletrodo, desvios no sistema hidráulico ou falhas provenientes na confecção da carga fria (sucata) provocando isolamentos e deslocamentos de sucata. Utilizando a equação abaixo, pode-se estimar o consumo de eletrodo. Através dela é possível afirmar que a corrente de trabalho possui forte influência, pois está elevada ao quadrado.

$$
\mathrm{Qs}(\mathrm{kg} / \mathrm{t})=3 \cdot \mathrm{K} \cdot\left(\mathrm{I}^{2} / \mathrm{P}\right) \cdot\left\{0,5+\left[0,25+\left(\mathrm{Kox} / \mathrm{K}^{\prime}\right) \cdot\left(\mathrm{D} / \mathrm{I}^{2}\right) \cdot \mathrm{H}\right] 1 / 2\right\} 2 \cdot \text { qee }
$$


Portanto, para redução do consumo de eletrodos foi priorizado a corrente de trabalho do FEA. Para verificar se existia oportunidade de redução foi elaborado um gráfico Potência x Corrente, onde foi verificado que no final de fusão (tanto do primeiro quanto do segundo cesto) e no refino se trabalhava em uma condição de ineficiência energética do arco elétrico, pois a corrente de trabalho já não contribuía para aumento da potência. Portanto, era possível reduzir a corrente sem prejudicar a potência do FEA e, consequentemente, a produtividade do FEA. Isto pode ser visto na Figura 6.

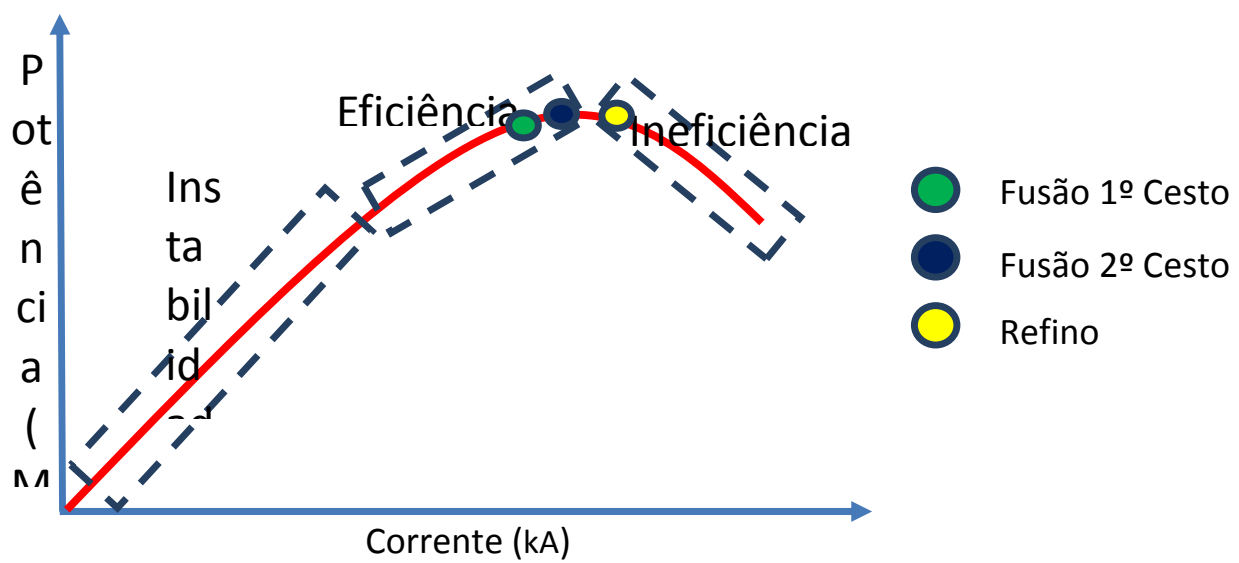

Figura 6. Curva Esquemática Potência x Corrente antes da mudança

Com a redução da corrente e algumas ações relacionadas aos parâmetros do regulador de eletrodos que minimizaram o número de quebras de fase, houve redução de $12 \%$ no consumo de eletrodo, de acordo com a Figura 7.

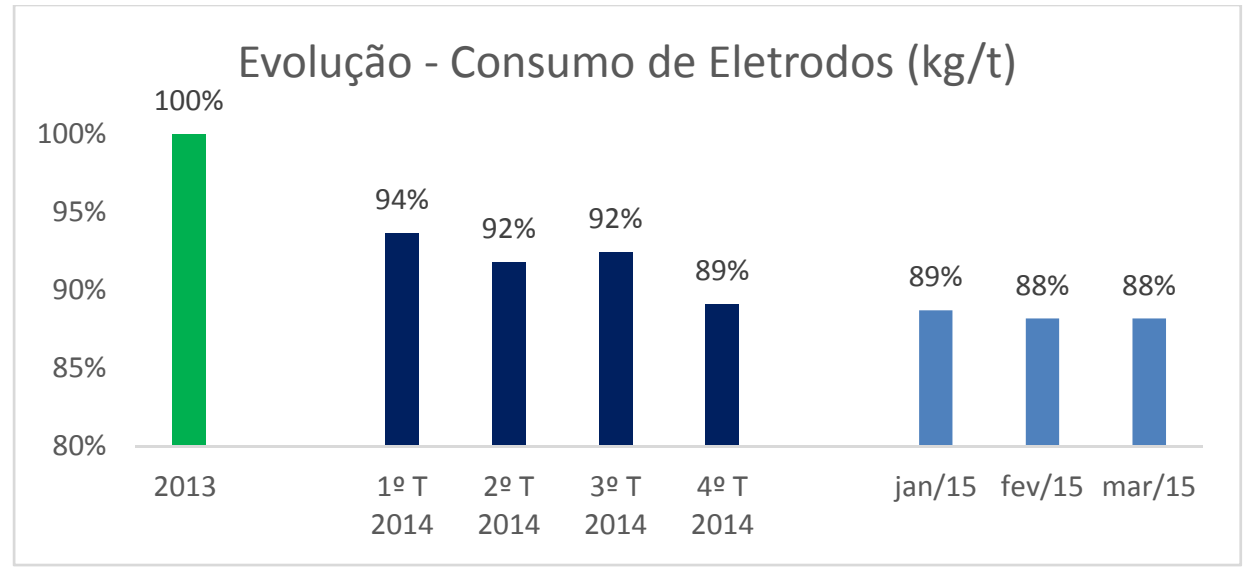

Figura 7. Evolução do consumo de eletrodos

\subsection{Energia Elétrica}

De acordo com John [2], o incremento da energia química (traduzida principalmente pelas reações de oxidação e combustão que ocorrem no forno) contribui para a redução do consumo de energia elétrica. No tocante aos queimadores, a capacidade energética do gás natural é de 9,3 a $10,7 \mathrm{kWh} / \mathrm{m}^{3}$ devido sua combustão. Quanto aos injetores de oxigênio, a capacidade energética pode chegar até $5 \mathrm{kWh} / \mathrm{m}^{3}$, embora usualmente seja considerado valores entre $3,5-3,7 \mathrm{kWh} / \mathrm{m}^{3}$. 
Portanto, para redução do consumo de energia elétrica foi priorizado o aumento no consumo de gás natural, além de trabalhar no aumento da eficiência do queimador através da alteração da rampa de vazão do gás. Conforme a Figura 7, a eficiência do queimador vai sendo reduzida ao longo da fusão.

Na Figura 9 está a evolução do consumo de energia elétrica da aciaria, enquanto na figura 8 observa-se um gráfico consumo de gás natural $x$ consumo de energia elétrica.

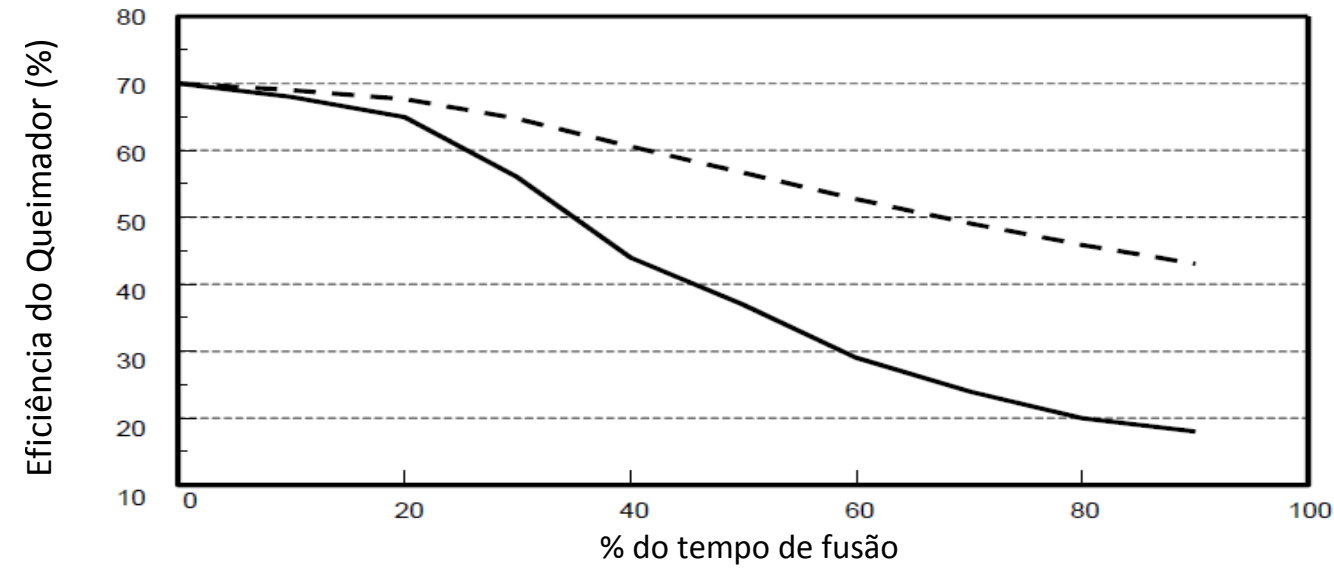

Figura 7. Eficiência do queimador instantânea (linha contínua) e acumulada (linha pontilhada). Fonte: Pretorius et. al [3].

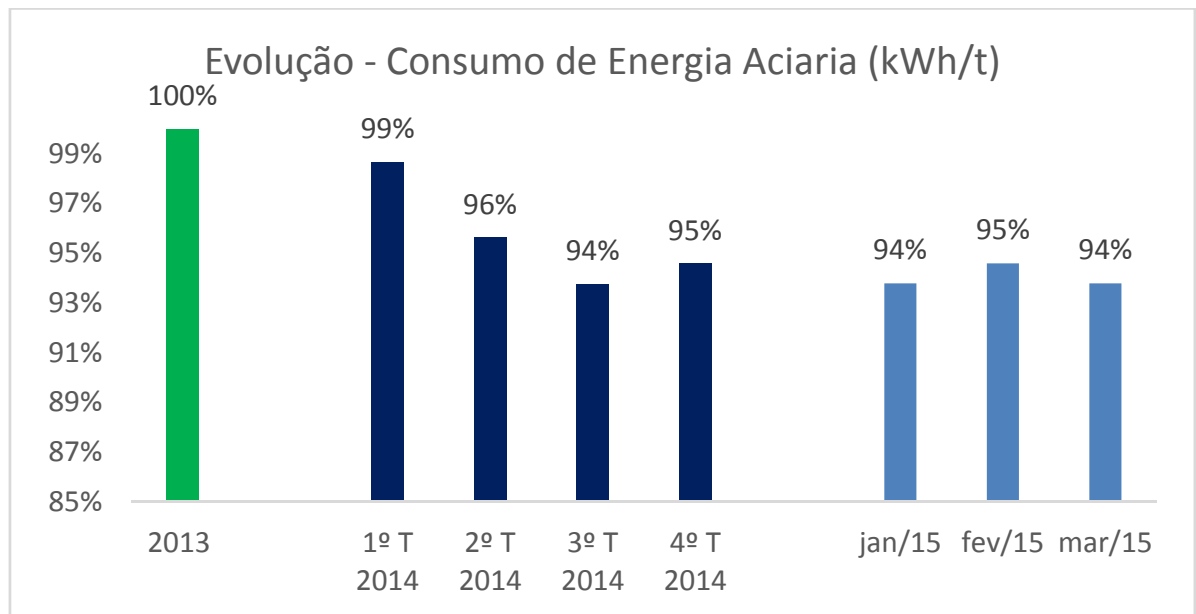

Figura 8. Evolução do consumo de energia total aciaria.

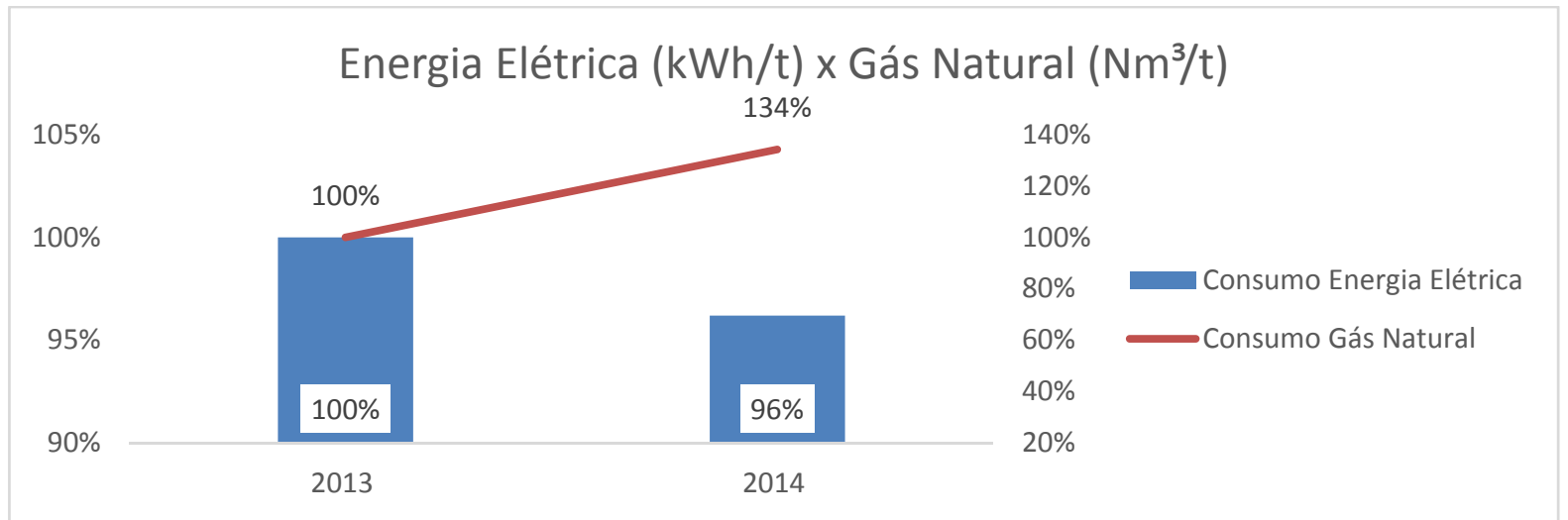

Figura 9. Consumo de Gás Natural x Consumo de Energia Elétrica. 
Além disso, houve alteração na especificação do grau de aço para aplicação CA-60, alterando a faixa de carbono. De acordo com a figura 10, é necessário um maior tempo de processo para atingir menores teores de carbono. Dessa forma, espera-se que com maior teor de carbono, menor será o Power On e, por consequência, o consumo de energia elétrica. A comparação entre os graus de aço pode ser vista na figura 11 .

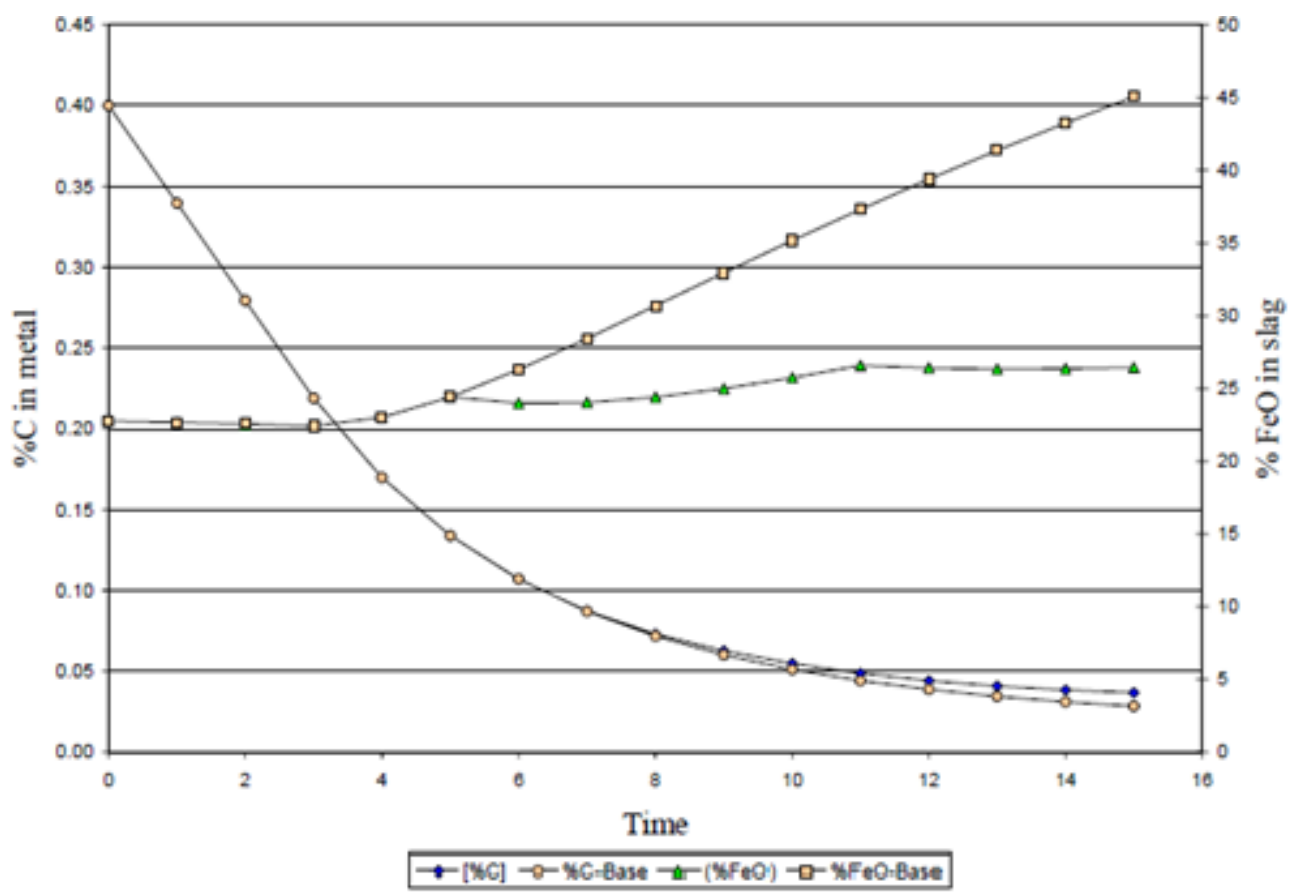

Figura 10. Tempo de processo em função do teor de carbono final. Fonte: Pretorius et. al [3]

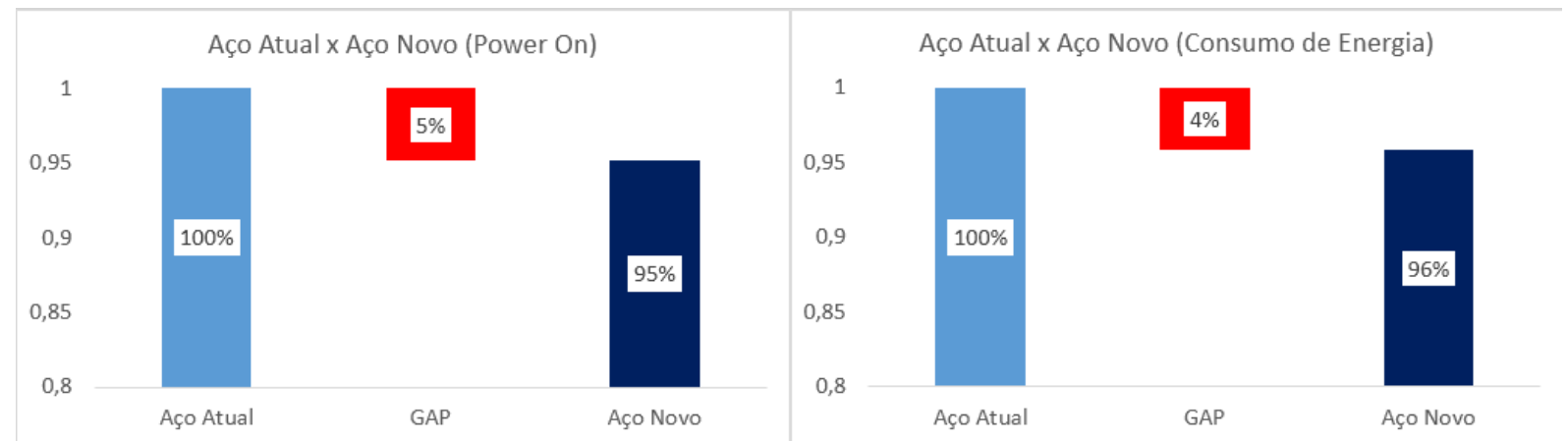

Figura 11. Comparação de Power On (minutos) e Consumo de Energia Elétrica (kWh/t) entre aço atual e aço novo.

\subsection{Carbureto de Cálcio}

O carbureto de cálcio tem sido amplamente utilizado em processos de aciaria. De acordo com Cardoso Filho et. al [4], tanto pode ser utilizado para desoxidação do aço (principalmente no vazamento da corrida), como também para desoxidação da escória (Refino Secundário) visando a melhoria do processo de dessulfuração.

No caso da Votorantim Resende, o $\mathrm{CaC}_{2}$ é utilizado no Forno Panela, objetivando redução dos óxidos de ferro e manganês (FeO e $\mathrm{MnO}$ ). Este processo pode ser visto nas equações 2 e 3 .

$$
\mathrm{CaC} 2(\mathrm{~s})+3 \mathrm{FeO}(\mathrm{l}) \rightarrow \mathrm{CaO}(\mathrm{s})+3 \mathrm{Fe}(\mathrm{l})+2 \mathrm{CO}(\mathrm{g})
$$




$$
\mathrm{CaC} 2(\mathrm{~s})+3 \mathrm{MnO}(\mathrm{l}) \rightarrow \mathrm{CaO}(\mathrm{s})+3 \mathrm{Mn}+2 \mathrm{CO}(\mathrm{g})
$$

Utilizando as reações acima, pode-se calcular a quantidade estequiométrica necessária de $\mathrm{CaC}_{2}$ necessária para reduzir o $\mathrm{FeO}$ e $\mathrm{MnO}$ na escória do Forno Panela. Portanto, visando obter o teor médio destes óxidos na escória de panela foram levantadas 100 amostras de escória do início de processo do FP. Após o levantamento, constatou-se que o Padrão de Processo em vigência solicitava uma adição 3 vezes maior do que o requerido pelo cálculo estequiométrico. Dessa forma, após alguns testes, o padrão foi revisado. A evolução do consumo de CaC2 está presente na figura 12 .

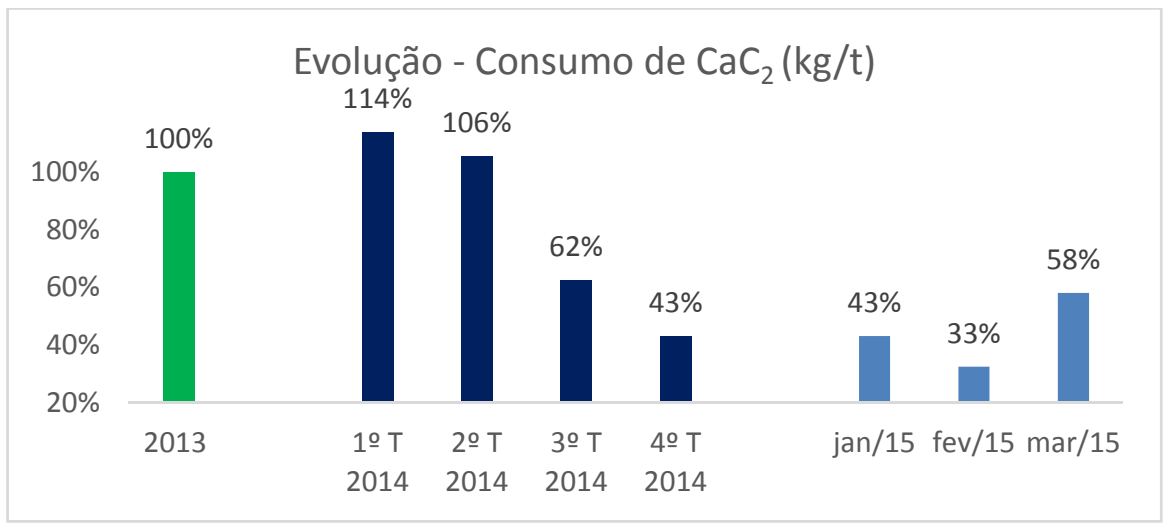

Figura 12. Evolução do consumo de carbureto de cálcio.

Duas preocupações ao iniciar a ação seria o possível impacto na dessulfuração no Forno Panela, pois além de desoxidar a escória $\mathrm{O}^{\mathrm{CaC}_{2}}$ também participa diretamente do processo de remoção de enxofre. Outra preocupação é o aumento do desgaste refratário, que poderia ser potencializado caso o nível de oxidação da escória aumentasse ou se o consumo de fluorita fosse incrementado devido uma possível dificuldade em dessulfurar. Porém, não houve prejuízo nestes indicadores.

\subsection{Ligas Metálicas}

As ferro-ligas são utilizadas no processo de aciaria para realizar a desoxidação e também para fornecer elementos como Manganês, Silício, Boro, Nióbio ao aço. $\mathrm{Na}$ Votorantim Resende as ligas com maior consumo são FeSi e FeSiMn, portanto as ações foram voltadas para estes materiais. A primeira ação foi a criação de uma ferramenta para otimização de custo de ligas, levando em consideração grau de aço, disponibilidade de silos, preço das ligas disponíveis. Com isso, foi possível diminuir o consumo de $\mathrm{FeSi}$, conforme gráfico na figura 14.

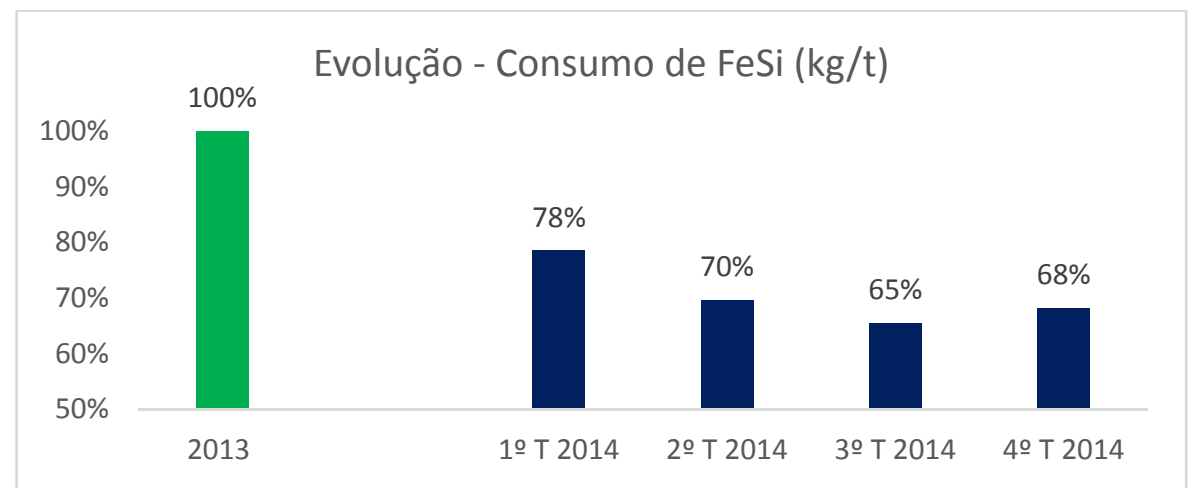

Figura 14. Evolução do consumo de FeSi 
Quanto ao FeSiMn, a principal ação foi a redução do teor de $\mathrm{Mn}$ em todos os aços. Para atingir este resultado foi necessário trabalhar no teor de enxofre (foi reduzido em $25 \%$ ) de chegada no Forno Panela, aumentando a capabilidade de atendimento da relação $\mathrm{Mn} / \mathrm{S}$. O teor de enxofre na chegada do FP foi reduzido em $25 \%$ enquanto o \%Mn final foi reduzido em $12 \%$. A evolução do consumo do FeSiMn está na figura 16.

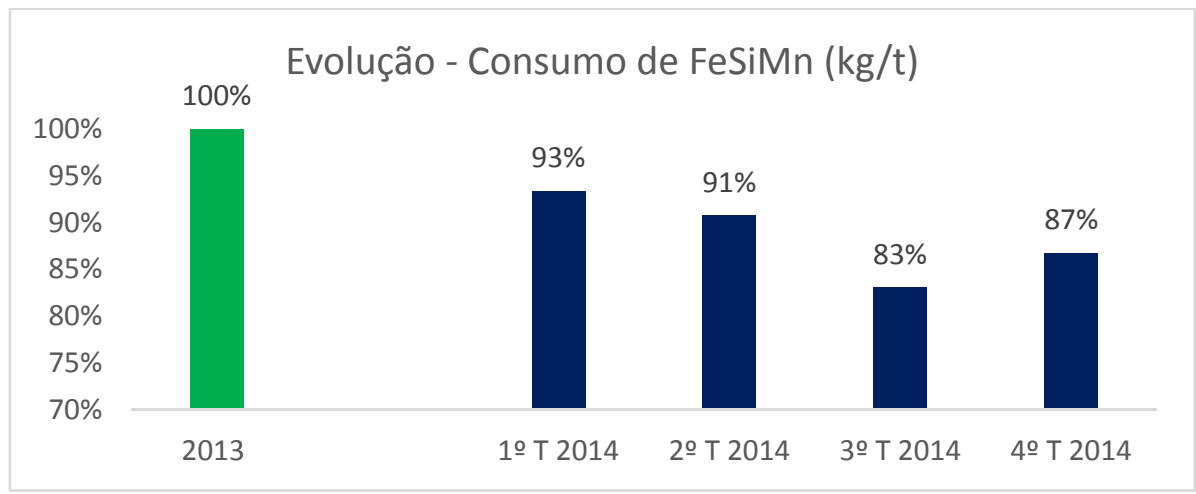

Figura 16. Evolução do consumo de FeSiMn

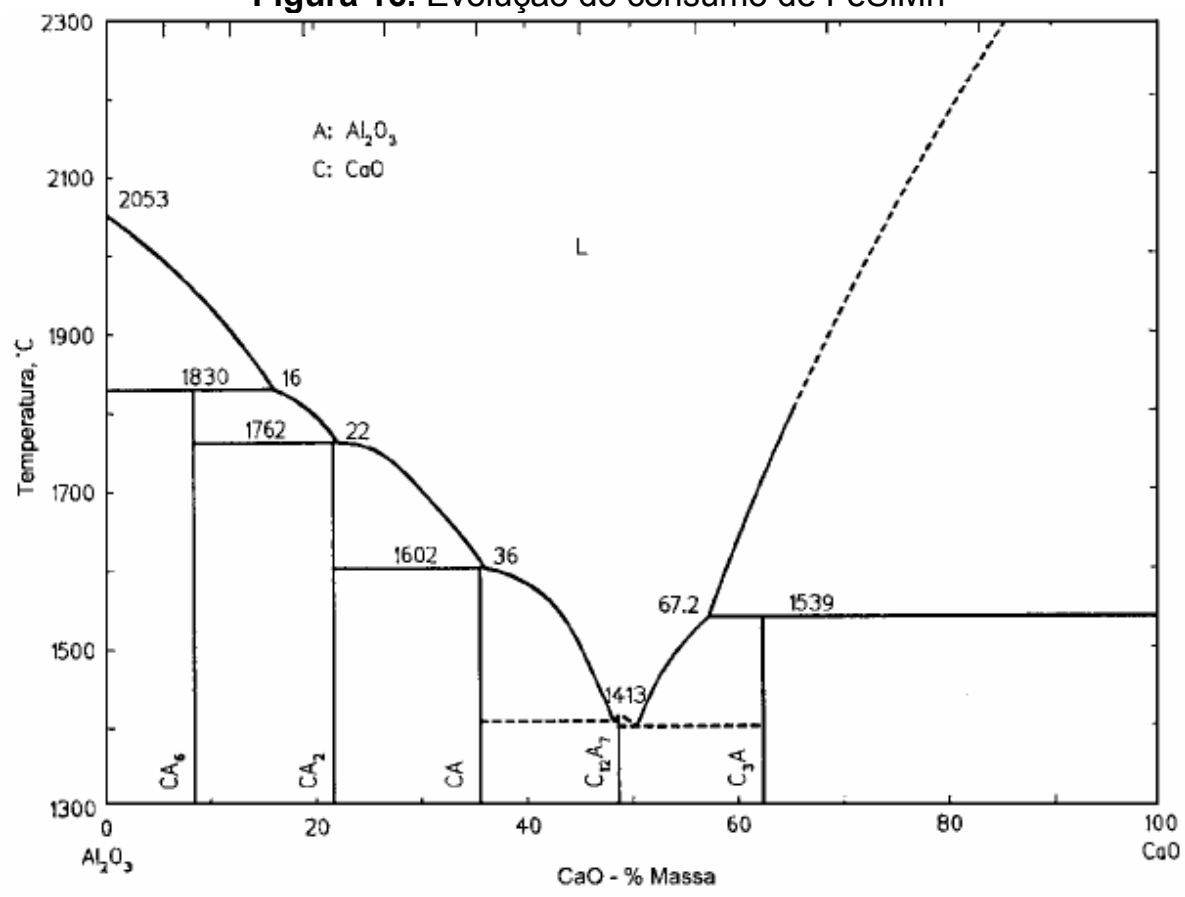

Figura 17. Diagrama de fases $\mathrm{CaO}-\mathrm{Al}_{2} \mathrm{O}_{3}$ Fonte: Silva Júnior, V. G.[5]

O CaSi possui pequeno impacto no consumo de ligas, porém é relevante no que diz respeito ao custo. A função do CaSi é interagir com a alumina $\left(\mathrm{Al}_{2} \mathrm{O}_{3}\right)$ alterando a morfologia destas inclusões, que é não deformável, e reduzindo seu ponto de fusão (conforme figura 17), fazendo com que esta inclusão fique líquida durante o processo de lingotamento contínuo. Isto contribui para melhoria da lingotabilidade devido à redução do evento chamado clogging.

$\mathrm{Na}$ Votorantim Resende realiza-se desoxidação ao silício, portanto a utilização do Ca-Si para interagir com a $\mathrm{Al}_{2} \mathrm{O}_{3}$ não é efetivo, afinal a formação deste óxido não é intensa. Inclusive, dependendo do teor de enxofre $(>0,025 \%)$ no Forno Panela, o 
tratamento contribuirá para formação de outras inclusões, principalmente o CaS, que apresenta ponto de Fusão de $2000^{\circ} \mathrm{C}$, e portanto também prejudica a lingotabilidade, conforme figura 18. Dessa forma, baseado nas considerações acima a adição de CaSi foi eliminada para alguns aços dos aços.

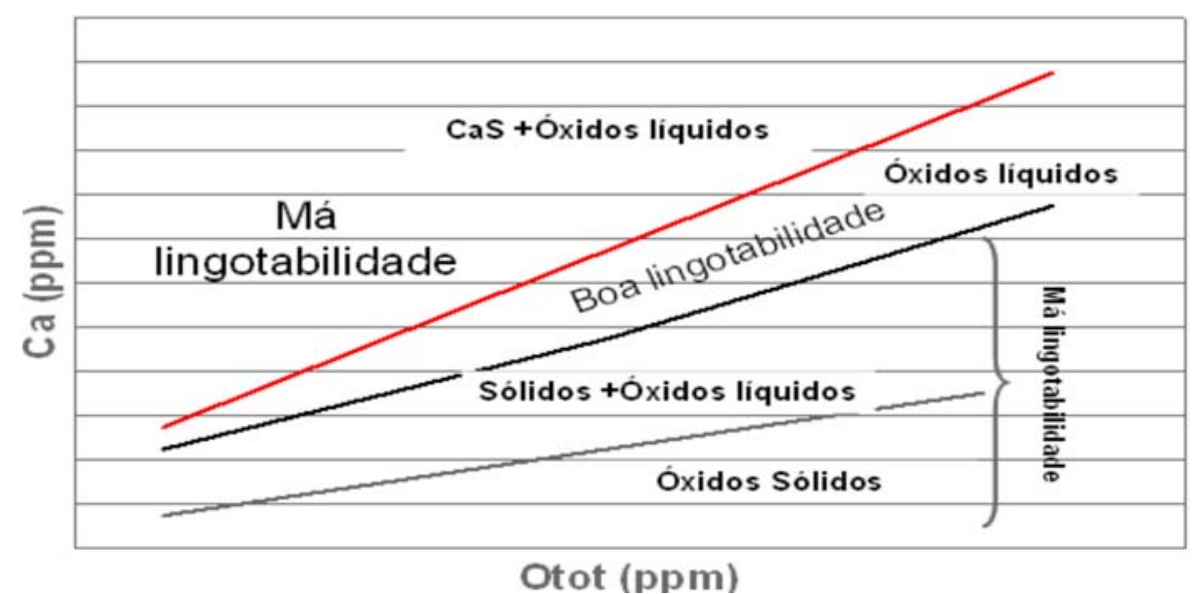

Figura 18. Lingotabilidade em função dos teores de Calcio e Oxigênio total do aço. Fonte: Magalhães, H. L. G [6]

\section{CONCLUSÃO}

A utilização do DMAIC para priorizar e atacar o custo de transformação se mostrou eficaz, pois proporcionou considerável redução de custo e de baixo investimento. No que diz respeito ao aspecto técnico, podem ser listadas as seguintes conclusões:

- A redução da corrente do FEA foi vital para redução do consumo de eletrodos, sem impactos no Power On. No tocante às quebras de eletrodos, o correto ajuste do regulador foi importante.

- Quanto ao consumo de energia, o incremento no consumo de gás natural e o aumento da eficiência do queimador teve sucesso na redução do indicador.

- A utilização de otimizadores de custo de ligas são úteis para garantir a utilização do mix mais barato. Quanto ao consumo de FeSiMn, a redução do \%Enxofre de chegada no Forno Panela foi fundamental para redução do teor de $\mathrm{Mn}$. Em relação ao Ca-Si, a redução expressiva em seu consumo contribui fortemente na redução de custo, afinal sua utilização não era tecnicamente justificada.

- Finalmente, foi possível reduzir o consumo de carbureto de cálcio sem atrapalhar a dessulfuração no forno panela e sem danos ao refratário de panela.

\section{REFERÊNCIAS}

1 Jaccard L. R. Consumo Específico de Eletrodos em Fornos Elétricos a Arco Correlação com os Fatores de Operação. 2003 [acesso em abr. 2015]. Disponível em: http://jaccard.com.br/consumo.htm

2 John, Alexandre Liborio. Dissertação de Mestrado Melhorias no Desempenho dos Injetores Supersônicos em Operação em um Forno Elétrico a Arco.UFRS 2009. [acesso em abr. 2015]; Disponível em: http://www.lume.ufrgs.br/bitstream/handle.

3 Eugene Pretorius e Helmut Oltmann. The EAF operating cycle - Charging, melting and refining. LWB Refractories - Process Technology Group. Página 20 e 34 
4 Cardoso Filho et. al. Carbureto de Cálcio: Uma Alternativa Eficiente ao Uso de Alumínio. 2013 [acesso em mar. 2015]. Volume 10: página 28-34. Disponível em: http://dx.doi.org/10.4322/tmm.2013.004

5 Silva Júnior, V. G. Dissertação de Mestrado Verificação do efeito da injeção de gás através de válvulas submersas multiporos sobre a lingotabilidade e limpeza do aço. Programa de Pós-Graduação em Engenharia de Minas, Metalúrgica e de Materiais PPGEM. Porto Alegre 2009.

6 Magalhães, H. L. G. Dissertação de Mestrado Melhoria da limpidez do aço SAE 1045 desoxidado ao alumínio com aplicação na indústria automobilística, utilizando termodinâmica computacional. Programa de Pós-Graduação em Engenharia de Materiais da REDEMAT. Ouro Preto 2010. 